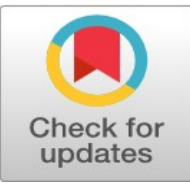

PRIMARY RESEARCH

\title{
Social media in the service of social entrepreneurship: Identifying factors for better services
}

\author{
Jamal El-Den ${ }^{1 *}$, Pratap Adikhari ${ }^{2}$, Sami Azam ${ }^{3}$ \\ 1, 2, 3 Charles Darwin University, School of Engineering and IT Darwin, Australia
}

\section{Key Words \\ Migrant workers \\ Remittances \\ Determinants \\ Intention to return}

Received: 8 October 2016

Accepted: 20 February 2017

Published: 21 April 2017

\begin{abstract}
This research provides a detailed literary investigation of current literature on social media and social entrepreneurship. A conceptual framework that depicts the role of social media in social entrepreneurship is developed. Furthermore, extensive research on the different technology adoption theories and frameworks was conducted to identify key social media factors for social entrepreneurial adoption. A social media adoption model has been proposed that depicts the adoption steps and integrates the identified factors as the key to the adoption process. The analysis shows that intention to return home induces remittances in terms of amount per year and proportion to income. Having further considered the determinants to return home of workers, income and employment satisfaction seem not to affect their decisions as hypothesized significantly. On the other hand, they are preferably satisfied in legal issues, particularly visa regulations and labor protection, and they became important negative factors of intention to return. This research provides valuable insights into social media's role in social entrepreneurship and the social media adoption process in social enterprises. Social entrepreneurs can use the findings of this research to facilitate the social media adoption process in their entrepreneurial ventures and can be used by academics for further research.
\end{abstract}

(C)2017 The Author. Published by TAF Publishing.

\section{INTRODUCTION}

\section{Social Entrepreneurship}

Social Entrepreneurship is a simple term with diverse meanings (Trexler, 2008). The term "social entrepreneurship" was first used in the literature in social changes in the 1960s and 1970s (Banks, 1972) and it came into widespread use in the 1980s with the work of Bill Drayton of Asoka, funding social innovators around the world (Dees, 2007). The concept of social entrepreneurship has gained popularity especially after the publication of "The Rise of the Social Entrepreneur" by Charles Leadbeater (cited in Mair and Ignasi 2006). It was among the first research works on social entrepreneurship that provides fundamental theoretical view within the field.

Although the concept of social entrepreneurship is new, the practice of social entrepreneurship is far from new. Social entrepreneurs have always existed in our society but with different names, such as humanitarians, philanthropists, reformers, saints, or great leaders (Bornstein and Susan, 2010). After 1990, the field started to gain attention from governments and academics (Dees, 2007).

Currently, social entrepreneurship is being used in a variety of sectors. It has become

\footnotetext{
${ }^{*}$ Corresponding author: Jamal El-Den

†Email: Jamal.El-Den@cdu.edu.au
} 
increasingly prominent in the society due to the growing social and environmental problems. Social entrepreneurship addresses the social problems, such as poverty, infirmity, illiteracy, environmental destruction, and makes life worth living for many people (Bornstein and Susan, 2010; Mai and Bui, 2015).

It is distinct from other forms of entrepreneurship as it combines social causes with business principles. It has been recognized as a new type of entrepreneurship that is primarily focused on generating social wealth rather than creating economic wealth (Dees, 2007). Social entrepreneurship has become an immense tent which includes all kinds of socially beneficial activities (Martin and Sally, 2007).

Different researchers have interpreted and defined social entrepreneurship in many different ways. Social entrepreneurship can be defined as a non-profitable practice that seeks alternative funding strategies, or management schemes to generate social value (Austin et al., 2006). Social entrepreneurship is referred to as the socially liable initiatives of businesses engaged in cross-sector partnerships (Sagawa and Eli, 2000). Social entrepreneurship is a means to improve societal problems and catalyze social change (Alvord et al., 2004). Most existing definitions on social entrepreneurship are based on the following two characteristics:

1) Social entrepreneurship combines resources in new ways to create social value.

2) Social entrepreneurship is primarily motivated to generate benefits to society.

Impact of Social Entrepreneurship in the Society

Social entrepreneurship significantly contributes to societies by generating social values and resolving social and environmental issues. The major impacts of social entrepreneurship in the society are: (Guo and Wolfgang, 2014).

i. Support during economic recession: During economic downturn, many people suffer and struggle to remain stable on a reduced income. Social entrepreneurs play critical role in solving such social problems by providing personal counselling, career counselling and job training (Guo and Wolfgang, 2014).

ii. Employment Development: Creating opportunities for employment is another major benefit of social entrepreneurship. Social enterprises create job and employment opportunity which is a significant economic value in itself (Guo and Wolfgang, 2014).

iii. Innovation: Innovation often plays important role in improving social welfare and promoting development in the society. With the increase in social entrepreneurial activities, new goods and services are being developed that are handling the issues like crime, abuse, illiteracy, mental health, and poverty in innovative ways (Guo and Wolfgang, 2014). iv. Equity promotion: Social entrepreneurship helps the most vulnerable population (homeless, disabled, unemployed people, women facing gender discrimination, at-risk youth) in the society by providing them training and employment (Jain, 2012).

\section{Social Media}

The era of social media probably started when Bruce and Susan Abelson in 1997 found a social networking site named "Open Diary", which brought together online diary writers into one community (Kaplan and Michael, 2010). The advancement in technology and availability of high speed internet access contributed to the creation of different social media applications such as Facebook, Twitter, YouTube, MySpace etc. The formal definition of social media requires the clarifications of Web 2.0 and User Generated Content (UGC). The term Web 2.0 was first used in 2004 to describe the World Wide Web, in a new way by providing a participatory and collaborative platform for users in which users are able to modify its contents and applications. The term User Generated Content (UGC) refers to 
different types of media contents that are created by users and are shared over the social media platforms.

Based on these clarifications of Web 2.0 and UGC, Social media can be defined as a group of internet-based applications built on the technological foundation of Web 2.0 that allows the creation and exchange of UGC (Kaplan and Michael, 2010). Social media use internetbased technologies to create interactive platforms by means of which people create, share, discuss, and modify contents.

Social media encompass blogs, discussion boards and chat rooms, email, websites and forums, and social networking websites. These media are being used extensively to transmit internet-based messages. Social media have become a key factor that influences various aspects of consumer behavior, opinions, attitudes, purchase behavior, communication, feedback and evaluation (Izhar, 2016; Mangold and David, 2009). Enterprises use social media tools to connect with their customers more effectively and build a strong relationship with them (Safko, 2012).

As January 2015, the total number of active social media accounts is 222 million, which is $29 \%$ of the world's total population (Kemp, 2015). The most dominant social media tool is Facebook, claiming 1.366 billion active users as of January 2015 followed by the Chineselanguage instant messaging software, $Q Q$ with 829 million active accounts (Kemp, 2015).

As of the end of 2014, 8 out of 10 enterprises use social media to facilitate their entrepreneurial activities while 3 in 5 of them have gained new customers via social media (Go-Gulf, 2013). The following table presents the statistics of adoption of different social media tools by enterprises having social media presence.

TABLE 1. Social Media Adoption in enterprises (Go-Gulf2013)

\begin{tabular}{ll}
\hline \hline Social Media & Adoption \% \\
\hline Facebook & $99 \%$ \\
Twitter & $97 \%$ \\
Google+ & $70 \%$ \\
Pinterest & $69 \%$ \\
Instagram & $59 \%$ \\
\hline \hline
\end{tabular}

\section{Social Media Presence of Social Enterprises}

The table below shows the summary of some social organizations and their presence in different social media platforms.

TABLE 2 . Social Media Adoption in enterprises (Go-Gulf 2013)

\begin{tabular}{|c|c|c|c|c|c|}
\hline S. No. & Social Enterprise & & & Social Media & \\
\hline & Website & Social Enterprise & Facebook & Twitter & YouTube \\
\hline 1 & Ashoka & www.ashoka.org/ & facebook.com/AshokaOrg & twitter.com/Ashoka (@ashoka) & youtube.com. com/user/Ashokavideos \\
\hline 2 & Grameen Foundation & www.grameenfoundation.org/ & https://www.facebook.com/StopPovertyNow & https://twitter.com/GrameenFdn (@GrameenFdn) & https://www.youtube.com/user/grameen \\
\hline 3 & TOMS & www.toms.com/ & https://www.facebook.com/toms & https://twitter.com/toms (@TOMS) & https://www.youtube.com/user/tomsshoes \\
\hline 4 & B Corporations & https://www.bcorporation.net/ & https://www.facebook.com/bcorporation & https://twitter.com/BCorporation (@Bcorporation) & https://www.youtube.com/user/bcorporations \\
\hline 5 & SEKEM & www.sekem.com & https://www.facebook.com/sekemgroup & https://twitter.com/sekemgroup (@sekemgroup) & https://www.youtube.com/user/sekeminitiative \\
\hline 6 & Blue Ventures & https://blueventures.org/ & https://www.facebook.com/blueventures & https://twitter.com/BlueVentures (@BlueVentures) & https://www.youtube.com/user/blueventures \\
\hline 7 & Send A Cow & https://www.sendacow.org/ & https://www.facebook.com/sendacow & https://twitter.com/SendaCow (@SendaCow) & https://www.youtube.com/user/sendacow \\
\hline
\end{tabular}




\section{SOCIAL MEDIA IN SOCIAL ENTREPRENEURSHIP CONCEPTUAL FRAMEWORK}

\section{Social Entrepreneurship}

Conceptual Framework The following is the research's conceptual framework that shows the role of social media in social entrepreneurship.

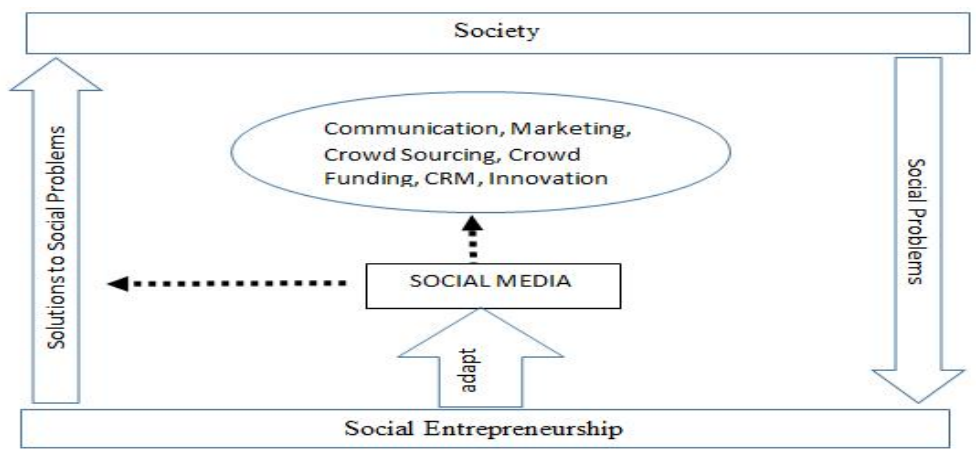

FIGURE 1. Social enterprises and their social media presence (Azam et al., 2016)

Social entrepreneurship thrives to solve problems that exist in the society. Figure-1, posits that adopting social media technology can assist social entrepreneurship to achieve its social mission. The social media create various opportunities such as effective communication, crowd sourcing, crowd funding, Customer Relationship Management, Innovation and marketing. Social enterprises can leverage these benefits from social media with the implementation of effective social media adoption process.

\section{Opportunities of Involvement in Social Media}

There are various kinds of opportunities and benefits for an enterprise to take part in social media. The most common opportunities that social media create for enterprises are listed below:

i. Communication (Mayo-Smith, 2010).

ii. Social media marketing: (Lukjanska, 2015).

iii. Social Customer Relationship Management (CRM): (Evans, 2010).

iv. Crowdsourcing: (Lukjanska, 2015).

v. Crowdfunding: (Lehner, 2013).

vi. Innovation: (Kotler et al., 2001) and (Evans, 2010).

\section{Social Media Adoption Process for Social Entrepreneurship}

Social media are widely adopted by social enterprises to facilitate the diverse activities and processes in their entrepreneurial ventures although to date the implementation and adoption of social media into the ventures are still difficult because of the unavailability of a standard way of effective adoption.

Social media can be a double-edged sword as they come with both opportunities and risks at the same time (Mortleman, 2011). Enterprises can benefit from the use of social media tools only if they understand the platform properly and utilize it in the right ways. Social enterprises should develop and implement a clear and comprehensible social media adoption process to ensure successful and fruitful adoption of social media strengths 
in their ventures. A successful social media adoption will enable the enterprises to leverage the full potential of the imbedded social media technology. A social media adoption process requires significant changes in the structure, process, culture and people of the enterprises. To date, a theory or method which drives social media technology adoption process is not available because such adoption still depends on the nature and type of the enterprise itself and the characteristics of the technology being adopted.

Figure- 2 is the research's proposed social media adoption process that we believe could be implemented in different social media enterprises. The adoption process may vary based on the nature and structure of the enterprise and the characteristics of the social media being adopted.

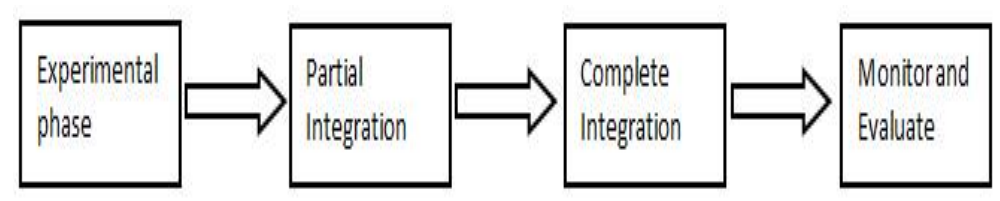

FIGURE 2 . Social media adoption process (Azam et al., 2016)

Technology Adoption Theories and Frameworks

Based on our extensive research, on different theories and frameworks to figure out the factors that influence social media adoption in the social organizations, we posit that there are different such factors which influence the social media adoption process. The different theories and frameworks discussed below are broadly used to explain the adoption of technology at firm level. These theories reveal different factors that influence the adoption process of technology in organizations. This research is novel in identifying these factors. Technology-organization-environment (TOE) framework: The TOE framework developed by Tornatzky and Fleishcher in 1990 serves as a useful framework for the analysis of technology adoption in organization (Sharif et al., 2015). The TOE framework suggests that the new technologies' adoption in the organizations is determined by the influence and interaction of the three basic TOE factors. Technology factor incorporates both the internal and external technologies of the organization. The Organizational context includes different factors such as firm size and scope, organizational structure, quality of employees, etc. The Environmental context includes the industry, audience, competitors, resources, government policies, etc.

Diffusion of innovation theory: Diffusion of Innovation Theory was propounded by Roger in 1995. DOI Theory suggests that adoption of social media technology at firm level is influenced by the organizational culture, practices, individual needs, innovativeness and norms of the technology (Rogers, 2003). It has five significant characteristics. They are relative advantage, compatibility, complexity, and trial ability and observability.

Institutional theory: The institutional theory was first introduced by Weber in 1946 and Teo et al. used the institutional theory to investigate the adoption of information technology at the firm level (Tan, 2012). It suggests that adoption of technology is motivated by the social and cultural factors and the external pressures from competitors, trading partners, customers, and government rather than internally driven decision.

\section{Hypotheses and Model}

Figure-3 shows the research's identified factors and how they interact. We posit that these factors are integral to the adoption process of social media technology in the social enter- 
prises.

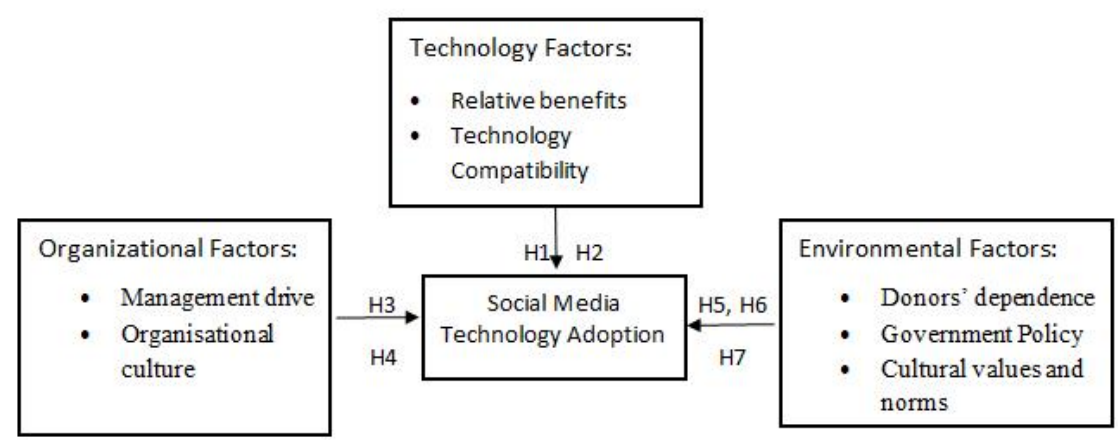

FIGURE 3 . Factors affecting social media technology adoption (Azam et al., 2016)

\section{Technology Factors}

Technology Factors describe the technology characteristics that can influence the adoption process. Based on different theories and frameworks, the technology characteristics for social media adoption are technology relative advantages, and technology compatibility.

Relative advantage: Technology benefits refer to the enhanced service quality from the use of adopted technology. Different social media tools provide different types of functionality. The selection of a particular social media tool depends on the comparative benefits that it provides over other available tools. The higher the level of relative benefits, the higher the likelihood of adopting the social media tool. Thus, the following hypothesis can be derived:

H1: Social enterprises are more likely to adopt and use social media tools with comparatively higher benefits.

Technology compatibility: The technology compatibility refers to normative compatibility and operational compatibility (Karahanna et al., 2006). Normative compatibility refers to the compatibility issues with what the users think about the new technology while the operational compatibility refers to the compatibility of the new technology with the existing technology structure of the organization. The organization is more likely to adopt such social media tools which are compatible with the people and the processes of the organization. Thus, the following hypothesis can be derived:

H2: Social enterprises are more likely to adopt and use social media tools with better compatibility.

\section{Organisational Factors}

The organizational factors refer to the organizational characteristics that can influence the adoption of social media technology in the organization. The adoption of social media technology could bring substantial changes in the structure and functions of the social organizations. Based on above discussed theories and frameworks, the adoption process of social media is influenced by different organizational factors. They are the management support and organizational culture.

Management drive: A supportive top management will facilitate the adoption process by supporting to overcome the adoption difficulties. The management support will encourage employees to adopt the new technology. The management support creates a positive 
environment in the organization and the level of commitment and participation among the employees in the organization will increase (Bruque and José, 2007). Thus, the following hypothesis can be derived:

H3: Management Drive has a positive impact on the adoption and use of social media technology in the social enterprises.

Organizational culture: The cultural factors of the organization such as the work structure, communication structure, policy and standards, control and coordination influence the decisions of utilization of the technology in the organization (Melitski et al., 2010). Different Research works have explored the relationship between organizational culture and individual adoption of technology in the workplace and have suggested that the culture in the organization shapes the process of adoption of social media technology in the organization (Melitski et al., 2010). Thus, based on Melitski et al. (2010) statement, the following hypothesis can be derived:

H4: Organizational Culture influences the adoption and use of social media technology in the social enterprises.

\section{Environmental Factors}

Environmental factors reveal the environmental characteristics that can influence the adoption of social media technology in the organization. The environmental factors include donors, end users, government support, cultural values and norms.

Donor dependence: Social enterprises always seek the help from the public in the form of crowd sourcing or crowd funding. Social media due their ease of accessibility from any part of the world provide a solid platform to communicate and coordinate with the public. This is vital for the existence and sustainable growth of the social enterprises since the high proportion of the social enterprise revenues is derived from the public contributions (Nah and Gregory, 2013). Thus, the following hypothesis can be derived:

H5: The social media adoption in the social enterprise is influenced by the donor preferences.

Government policy: Government policies may present both positive and negative opportunities for the social enterprises that may either encourage them to adopt social media or inhibit them from adopting the technology (Sharif et al., 2015). Social organizations seek support from the government for their existence and sustainable growth. The policies and regulations imposed by the government hugely influence the operational activities of the social enterprises. Based on Sharif et al. (2015) statement, the following hypothesis can be derived:

H6: The social media adoption in the social enterprise is influenced by the government policy.

Cultural values and norms: The decision of people to adopt technology is also determined by their perception of other's behavior towards the technology in the society. People tend to adopt technologies that are accepted by most of the people in their society. Word of mouth from friends, families, superiors and IT experts play a major role in the adoption of social media technology (Di Pietro et al., 2012). Thus, the following hypothesis can be derived: H7: The social media adoption in the social organizations is influenced by the cultural values and norms in the community.

\section{Conceptual Framework of Social Media Adoption}

Based on the understandings of the factors that affect social media adoption process in the social enterprises, we have developed a conceptual framework which depicts the overall social media adoption process in the social enterprises. The proposed model is an at- 
tempt to fulfil the needs of an effective social media adoption process for the social entrepreneurs. The social media adoption process can differ based on the nature and characteristics of the social media and the social enterprise itself. This process model can assist as a basic framework for social media adoption process for social enterprises.

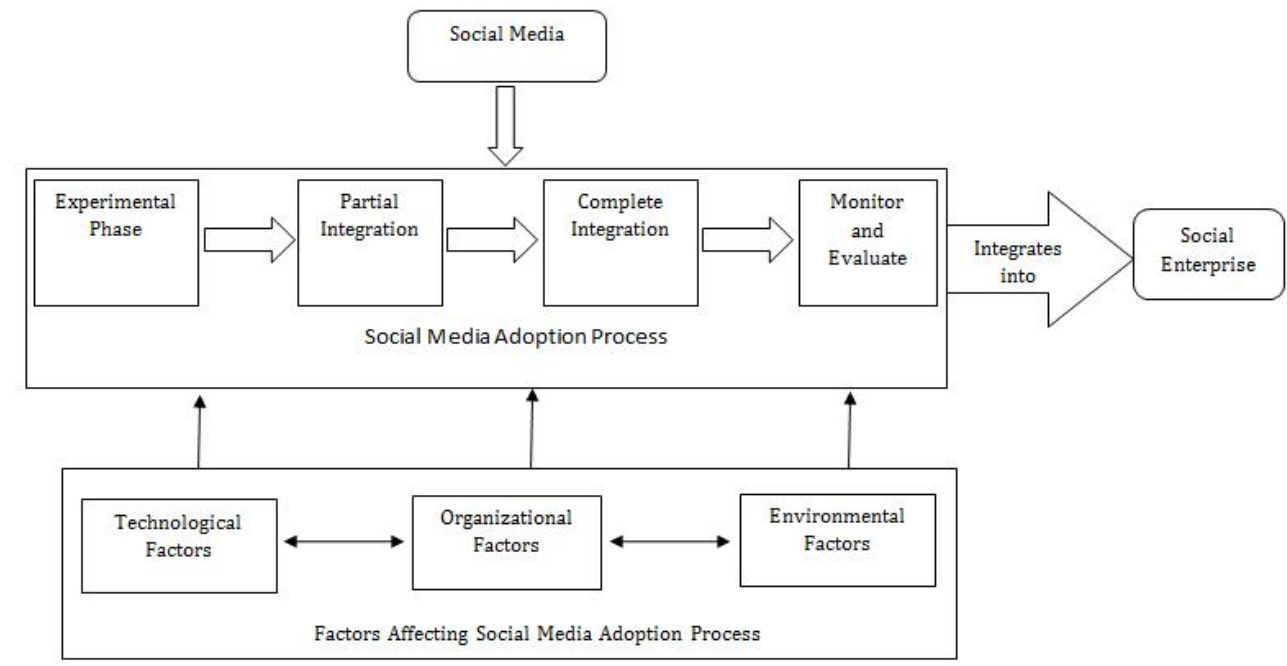

FIGURE 4 . Figure 4: Conceptual model of social media adoption process in social enterprises (Azam et al., 2016)

The above model posits that the social media adoption process in social enterprises involves four distinct phases and the adoption process is influenced by different factors. The different stages of adoption process are experimental phase, partial integration, complete integration and monitor and evaluate. Different activities related to adoption process are performed in each stage. In the experimental stage, social enterprises experiment with different social media tools and technologies to understand their behavior and characteristics. In the partial integration stage, social enterprises start to use social media in certain functions to support their activities.

In complete integration, social media is well-integrated in every department of the organization. And in the monitor and evaluate stage, the social enterprises monitor the social media regularly and evaluate their performance. The social media adoption process is influenced by different factors. Different theories and frameworks have been extensively investigated to determine the key factors that influence the adoption process. The different influential factors that are identified are relative advantage, technology complexity, management drive, organizational culture, government policy, donor dependence and cultural values and norms. Analyzing the key factors during the adoption process is very important as ignoring these factors can make the adoption process ineffectual. The proposed framework will be a great value for the entrepreneurs, generally social entrepreneurs. They can use this model as a useful framework for social media adoption process in their entrepreneurial ventures.

\section{CONCLUSION}

This research work provides valuable insights on the role of social media in social entrepreneurship and the social media adoption process in social enterprises. Bothsocial enterprises and business enterprises seek the assistance of social media to achieve their mission. Almost all organizations have already adopted or in the process of adoption of social media technology. The purpose of this paper is to investigate the role of social media 
in social entrepreneurship and formulate a model that can be used by social enterprises as a useful framework in their social media adoption process. A detailed research was performed on existing literature and a conceptual framework that depicts the role of social media in social entrepreneurship was developed. Factors which influence the adoption process were clearly identified in the research.

We strongly believe that the findings of this research can be used by social entrepreneurs to facilitate the social media adoption process in their entrepreneurial ventures and may also be the ground for further investigation by academics for further research.

\section{LIMITATIONS AND RECOMMENDATIONS}

The limitation of the proposed model is that it is designed for social enterprises and may not be so effective for other enterprises. However, other enterprises can use it as a helpful reference in their adoption strategy. The research focused on explanatory study on both domains, future researchers could perform quantitative study to figure out the statistical analysis of the role of social media in social entrepreneurship. Future researches can also explore other attributes of social media and social entrepreneurship.

\section{REFERENCES}

Alvord, Sarah HL., David Brown, and Christine W. Letts. 2004. Social entrepreneurship and societal transformation an ex- $\quad$ ploratory study. The Journal of Applied Behavioral Science 40, no. 3: 260-282.

Austin, James, Howard Stevenson, and Jane Wei-Skillern. 2006. Social and commercial entrepreneurship: Same, different, or both? Entrepreneurship Theory and Practice 30, no. 1: 1-22. D0I: 10.1111/j.1540-6520.2006.00107.x

Azam, S, Den JE and Adhikari P. 2016. The Role of Social Media in Social Entrepreneurship. Master thesis, Charles Darwin University, Casuarina, Australia

Banks, Joseph A. 1972. The sociology of social movements. London, UK: Macmillan. D0I: 10.1007/978-1-349-01452-1

Bornstein, David, and Susan Davis. 2010. Social entrepreneurship : What everyone needs to know. Oxford, UK: Oxford University Press.

Bruque, Sebastian, and José Moyano. 2007. Organisational determinants of information technology adoption and imple- $\quad$ mentation in SMEs: The case of family and cooperative firms. Technovation 27, no. 5: 241-253.

DOI: $10.1016 / j . t e c h n o v a t i o n .2006 .12 .003$

Dees, J. Gregory. 2007. Taking social entrepreneurship seriously. Society 44, no. 3, pp. 24-31.

DOI: $10.1016 /$ j.technovation.2006.12.003

Di Pietro, Loredana, Francesca Di Virgilio, and Eleonora Pantano. 2012. Social network for the choice of tourist destination: Attitude and behavioural intention. Journal of Hospitality and Tourism Technology 31, no. 1, 60-76.

DOI: $10.1016 /$ j.technovation.2006.12.003

Evans, Dave. 2010. Social media marketing : The next generation of business engagement. Hoboken, NJ: Sybex.

Go-Gulf. 2013. Social media usage in middle east-Statistics and trends [infographic]. URL: goo.gl/zx0oxq (accessed September 30, 2016).

Guo, Chao, and Wolfgang Bielefeld. 2014. Bryson Series in public and nonprofit management: Social entrepreneurship: An evidence-based approach to creating social value. Somerset, NJ: John Wiley\& Sons.

Izhar, Tengku AT., Mohammad Fazli B., Ahmad Nadzri M.,.... Wan Mohd HWH. 2016. Using ontology for goal-based query to evaluate social media data. Journal of Advances in Humanities and Social Sciences 2, no. 2: 108-118.

DOI: $10.20474 /$ jahss-2.2.5

Jain, Monika. 2012. Social entrepreneurship: Changing the world through social business models. Abhigyan 29. no. 4: ISSN: 2414-3111 
37-48.

Kaplan, Andreas M., and Michael Haenlein. 2010. Users of the world, unite! The challenges and opportunities of social Me- $\quad$ dia. Business Horizons53,no. 1, 59-68. DOI: 10.1016/j.technovation.2006.12.003

Karahanna, Elena, Ritu Agarwal, and Corey M. Angst. 2006. Reconceptualizing compatibility beliefs in technology accep- tance research. MIS Quarterly 30, no. 4, 781-804.

Kemp, S. 2015, We are social. URL: goo.gl/JtYjlC

Kotler, Philip, Gray Armstrong, John A. Saunders, and Veronica Wong. 2001. Principles of marketing. 2nd edition. New

York, NY: Pearson Education International.

Lehner, Othmar M. 2013. Crowdfunding social ventures: A model and research agenda. Venture Capital 15, no. 4, 289-311.

DOI: $10.1080 / 13691066.2013 .782624$

Lukjanska, Renate. 2015. How to choose proper business model for social enterprise. URL: goo.gl/mCf8no

Mai, Le Thi and Bui Loan T. 2015. Work-family role conflict: A survey of woman entrepreneurs in Hochiminh city. Interna-

tional Journal of Humanities, Arts and Social Sciences 1, no. 1: 36-47. DOI: 10.20469/ijhss.20006

Mair, Johanna, and Ignasi Marti. 2006. Social entrepreneurship research: A source of explanation, prediction, and delight.

Journal of World Business 41, no. 1, pp. 36-44. D0I: 10.1016/j.technovation.2006.12.003

Mangold, W. Glynn, and David J. Faulds. 2009. Social media: The new hybrid element of the promotion mix. Business Hori- $\quad$ zons 52, no. 4, 357-65. DOI: 10.1016/j.bushor.2009.03.002

Martin, Roger L., and Sally Osberg. 2007. Social entrepreneurship: The case for definition. Stanford Social Innovation

Review 5, no. 2, pp. 28-39.

Mayo-Smith, D. 2010. What social media really is. NZ Business 24, no. 4, 63.

Melitski, James, David Gavin, and Joanne Gavin. 2010. Te chnology adoption and organizational culture in public organiza- tions.

International Journal of Organization Theory and Behavior 13, no. 4, 546-68.

Mortleman, Jim. 2011. Social media strategies. Computer Fraud\& Security 2011, no. 5, 8-11.

DOI: $10.1016 /$ S1361-3723(11)70050-1

Nah, Seungahn, and Gregory D. Saxton. 2012. Modeling the adoption and use of social media by nonprofit organizations.

New Media \& Society.

Rogers, Everett M. 2003. Diffusion of Innovations. 5th ed. New York, NY: Free Press.

Safko, Lon. 2012. Social media Bible : Tactics, tools, and strategies for business success. 3rd ed. Hoboken, NJ: John Wiley \& Sons.

Sagawa, Shirley, and Eli Segal. 2000. Common interest, common good: Creating value through business and social sector

partnerships. California Management Review 42, no. 2: 105-122. D0I: 10.1016/j.technovation.2006.12.003

Sharif, M. Hisham M., Indrit Troshani, and Robyn Davidson. 2015. Public sector adoption of social media. Journal of Com- $\quad$ puter Information Systems 55, no. 4: 53-61. D0I: 10.1080/08874417.2015.11645787

Tan, Flix B. 2012. Global diffusion and adoption of technologies for knowledge and information sharing, IGI global. Hershey, PA: Publishing Systems Analysts.

Trexler, Jeff. 2008. Social entrepreneurship as an algorithm: Is social enterprise sustainable? Emergence: Complexity and

Organization 10, no. 3, p. 65-85. 